\title{
Next-generation sequencing for diagnosis of rare diseases in the neonatal intensive care unit
}

\author{
Hussein Daoud PhD, Stephanie M. Luco BSc, Rui Li PhD, Eric Bareke PhD, Chandree Beaulieu MSc, \\ Olga Jarinova PhD, Nancy Carson PhD, Sarah M. Nikkel MD, Gail E. Graham MD, Julie Richer MD, \\ Christine Armour MSc MD, Dennis E. Bulman PhD, Pranesh Chakraborty MD, Michael Geraghty MD, \\ Matthew A. Lines MD, Thierry Lacaze-Masmonteil PhD MD, Jacek Majewski PhD, Kym M. Boycott PhD MD, \\ David A. Dyment DPhil MD
}

See also www.cmaj.ca/lookup/doi/10.1503/cmaj.160490

Competing interests:

None declared.

This article has been peer reviewed.

Accepted: Feb. 23, 2016

Online: May 30, 2016

Correspondence to:

David Dyment, ddyment@ cheo.on.ca

CMAJ 2016. DOI:10.1503/ cmaj.150823

\begin{abstract}
Background: Rare diseases often present in the first days and weeks of life and may require complex management in the setting of a neonatal intensive care unit (NICU). Exhaustive consultations and traditional genetic or metabolic investigations are costly and often fail to arrive at a final diagnosis when no recognizable syndrome is suspected. For this pilot project, we assessed the feasibility of next-generation sequencing as a tool to improve the diagnosis of rare diseases in newborns in the NICU.
\end{abstract}

Methods: We retrospectively identified and prospectively recruited newborns and infants admitted to the NICU of the Children's Hospital of Eastern Ontario and the Ottawa Hospital, General Campus, who had been referred to the medical genetics or metabolics inpatient consult service and had features suggesting an underlying genetic or metabolic condition. DNA from the newborns and parents was enriched for a panel of clinically relevant genes and sequenced

$\Lambda$ rare disease is defined by a prevalence of less than 1 in 2000 individuals. $^{1}$ However, when considered in aggregate, $1 \%-2 \%$ of Canadians will manifest a rare disease in their lifetime., ${ }^{2,3}$ These disorders can present in the newborn period, and a third of these young children will succumb to the disease in their first year of life. ${ }^{3-5}$ Newborns who present with rare diseases typically require admission to a neonatal intensive care unit (NICU), where the standard of care includes exhaustive consultations and investigations to determine a molecular diagnosis. Reaching such a diagnosis is a challenge, given the considerable clinical and genetic heterogeneity associated with rare diseases; diagnosis is also confounded by the early stage of presentation, which is further accentuated in on a MiSeq sequencing platform (Illumina Inc.). The data were interpreted with a standard informatics pipeline and reported to care providers, who assessed the importance of genotype-phenotype correlations.

Results: Of 20 newborns studied, 8 received a diagnosis on the basis of next-generation sequencing (diagnostic rate $40 \%$ ). The diagnoses were renal tubular dysgenesis, SCN1Arelated encephalopathy syndrome, myotubular myopathy, FTO deficiency syndrome, cranioectodermal dysplasia, congenital myasthenic syndrome, autosomal dominant intellectual disability syndrome type 7 and Denys-Drash syndrome.

Interpretation: This pilot study highlighted the potential of next-generation sequencing to deliver molecular diagnoses rapidly with a high success rate. With broader use, this approach has the potential to alter health care delivery in the NICU. premature newborns. As a result, traditional genetic or metabolic investigations can be lengthy and expensive, and they often fail to arrive at a diagnosis in a timely manner. ${ }^{6}$

The current approach during a medical genetics consultation begins with a clinical assessment, followed by diagnostic testing that usually includes sequential testing of one or more candidate genes or panels of candidate genes. This step often requires approval for out-of-country testing, as only a limited number of gene tests are available for clinical testing in Canada. If the result of the first test is negative, the clinician may consider testing the next most likely candidate gene, frequently with diminishing returns. This approach can take months or years and can be a frustrating process for the patient, family 
and clinicians providing care. ${ }^{7}$ The inability to arrive at a timely and efficient diagnosis represents a substantial lost opportunity, as a diagnosis can limit or even halt further invasive, and at times futile, investigations for the neonate. Importantly, an accurate diagnosis informs prognosis and may guide management decisions.

The advent of next-generation sequencing has greatly advanced the ability to rapidly identify the novel genes responsible for disease. ${ }^{8}$ Wholeexome sequencing (sequencing of the coding portion of the genome) is beginning to be used on a clinical basis in tertiary care centres. ${ }^{9,10}$ In these initial clinical cohort studies, a molecular diagnosis was provided by whole-exome sequencing for about $25 \%$ of families. The proportion increased to $31 \%$ when the patient's parents were also analyzed. ${ }^{9}$ Another study used retrospective whole-genome sequencing to make a diagnosis in $57 \%$ of 35 children from the intensive care setting. ${ }^{11}$

Although whole-exome and whole-genome sequencing are powerful tools, important conditions are required for translation of these methods to the clinic or hospital setting. The availability of high-throughput sequencers, complex and costly infrastructure, and personnel with bioinformatics expertise are prerequisites. These resources may not be broadly available within some health care systems, and other strategies may be more relevant and effective.

Another attractive alternative is analysis based on next-generation sequencing that focuses only on the clinically relevant genes with known associated clinical phenotypes. ${ }^{12}$ This strategy offers several advantages over whole-exome or whole-genome sequencing interpretation of variants may be more straightforward, a higher depth of coverage can be readily achieved, and less infrastructure and fewer personnel are required - all of which contribute to a more rapid return of results.

For this pilot study, we evaluated the performance of a targeted next-generation sequencing panel that included 4813 "disease-relevant" genes in a cohort of newborns with rare disease in the NICU and assessed the effectiveness of this method to accurately diagnose these critically ill babies.

\section{Methods}

\section{Participants}

We recruited patients for this pilot study between January and December 2014 from the NICUs of 2 regional hospitals that together admit 2000 neonates, with various presentations, each year: the Children's Hospital of Eastern
Ontario and the Ottawa Hospital, General Campus. Research ethics approval for the study was obtained from the Children's Hospital of Eastern Ontario Research Board (protocol 08/71X).

We identified the patients retrospectively (i.e., after discharge from the NICU) or prospectively (i.e., during the NICU admission). The inclusion criteria were any newborn or infant with a currently undiagnosed complex medical presentation who had been, or was currently, admitted to the NICU and had been referred to the medical genetics or metabolics inpatient consult service of the study hospitals. Included neonates had to have at least one of the following findings: one or more congenital malformations, dysmorphic features, abnormalities in growth parameters, neurologic impairment (including encephalopathy, seizures or hypotonia) or features suggestive of a metabolic condition. Both parents were required for the consent process and for blood or saliva sampling. Participants were examined by a clinical geneticist or specialist in metabolics. Newborns with suspected chromosomal disorders (e.g., trisomy 18) or conditions thought to be largely nongenetic (e.g., fetal alcohol spectrum disorder, diabetic embryopathy) were excluded.

\section{Next-generation sequencing and data analysis}

We extracted genomic DNA from lymphocytes according to standard methods. The DNA samples were enriched for 4813 genes with known associated clinical phenotypes using the TruSight One Sequencing Panel kit (Illumina Inc.). This panel includes genes from the Human Gene Mutation Database (www.hgmd.cf.ac.uk/ ac/index.php) and the Online Mendelian Inheritance in Man database (www.genetests.org), along with other genes identified from commercially available panels. Enriched libraries were pooled and sequenced in a trio approach (newborns and parents) on the MiSeq instrument (Illumina Inc.), according to the manufacturer's recommendations for paired-end 150 base pair reads. The MiSeq Reporter Software (Illumina Inc.) was used for adaptor trimming, sample demultiplexing and FASTQ file generation.

We used the NextGene software (SoftGenetics LLC) for data processing, alignment, variant calling and annotation. The average coverage of the target bases was $97 \times$, with $97.7 \%$ of the regions of interest having at least $10 \times$ coverage and $95.0 \%$ having at least $20 \times$ coverage (Appendix 1, available at www.cmaj.ca/lookup/suppl/ doi:10.1503/cmaj.150823/-/DC1). We analyzed the next-generation sequencing data from each trio under all modes of inheritance (de novo dominant, autosomal dominant, recessive or 
$\mathrm{X}$-linked) using the variant comparison tool of the NextGene viewer. The lists of variants were subsequently reduced by filtering out those with a minor allele frequency greater than $1 \%$ in either the 1000 Genomes project (February 2012 data release) or the National Heart, Lung and Blood Institute Exome Sequencing Project (January 2013 data release).

All candidate mutations were inspected visually using the NextGene viewer and the Integrative Genomics viewer (Broad Institute) to exclude obvious false-positive results. Candidate genes were discussed with the clinicians involved in patient care to assess the importance of genotype-phenotype correlation. Finally, all disease-causing mutations were confirmed by Sanger sequencing, and segregation was tested in the appropriate family members.

\section{Results}

We recruited 20 patients (14 boys and 6 girls) and their parents for this pilot study. The clinical descriptions of the newborns included in the study are summarized in Table 1 . Of these 20 patients, 10 presented with neurologic signs or symptoms (e.g., hypotonia, seizures), and 6 presented with multiple malformations. Two of the 20 newborns had a family history of a similar complex medical presentation, and 3 were born to consanguineous parents. Of the 20 newborns, 12 were enrolled in this pilot study after discharge from the NICU (retrospective) and 8 were enrolled while admitted to the NICU (prospective). The clinical investigations undertaken for these patients are summarized in Table 2.

Next-generation sequencing provided a molecular diagnosis for 8 of the 20 newborns, for a diagnostic rate of $40 \%$. The diagnoses (and associated genes) were renal tubular dysgenesis (ACE), SCNIA-related encephalopathy syndrome (SCN1A), X-linked myotubular myopathy (MTM1), FTO deficiency syndrome (FTO), cranioectodermal dysplasia (WDR19), congenital myasthenic syndrome (CHRND), autosomal dominant intellectual disability syndrome type 7 (DYRK1A) and Denys-Drash syndrome (WTI) (Table 3).

For 2 of the newborns (cases 8 and 15), standard-of-care (nonresearch) sequencing resulted in molecular diagnoses. In case 8 , a targeted candidate gene (MTMI) was Sanger sequenced, and in case 15 , a next-generation sequencing-based panel of genes $(n=18)$ was sequenced. Both of these tests were performed in an out-of-country clinical diagnostic laboratory. The diagnostic rate in the consanguineous families was 3 of 3 (100\%), although 1 of these newborns had a de novo mutation (case 18).

The time to return of results ranged from 2 to 58 weeks (mean $15.2 \mathrm{wk}$ ). The time for return of results was not a primary outcome measure, and the wide variability reflected the limited availability of the MiSeq platform for research purposes. Short case histories for each of the patients with a molecular diagnosis are provided in Appendix 2, available at www.cmaj.ca/lookup/ suppl/doi:10.1503/cmaj.150823/-/DC1.

Of the 8 patients in this study for whom a diagnosis was made by next-generation sequencing, 2 individuals had a change in medical management because of the diagnosis. For the patient with $A C E$ mutations (case 2), the molecular diagnosis guided subsequent assessment of aldosterone and the initiation of fludrocortisone, which ultimately resulted in improved kidney function. ${ }^{13}$ In the other patient (case 19), diagnosis of a de novo WT1 mutation altered plans for surgical management. Both kidneys are to be removed during kidney transplant, to reduce the substantial risk of Wilms tumour should the kidneys not be removed. Knowledge of the diagnosis in the other 6 cases provided beneficial information to care providers about the natural history and prognosis and allowed accurate counselling about recurrence risk and prenatal diagnosis.

\section{Interpretation}

Next-generation sequencing has the potential to rapidly transform the practice of clinical genetics. In particular, newborns admitted to the NICU with rare and complex diseases may benefit substantially from a timely molecular diagnosis through next-generation sequencing. There are several approaches to next-generation sequencing, and we opted to restrict sequencing to a comprehensive panel of genes understood to be disease-relevant. This choice allowed us to circumvent the challenges associated with massive data sets, infrastructure and variant interpretation. The diagnostic success rate within our study was $40 \%(8 / 20)$, comparable to that achieved with larger cohorts $(22 \%-31 \%)$ on the basis of clinical whole-exome sequencing. ${ }^{9,10}$

One of the most important advantages of a focused panel approach is that testing can be performed in a hospital-based molecular laboratory, using smaller and more affordable nextgeneration sequencing platforms, rather than the larger infrastructure that is often found only in dedicated genomics centres. As such, samples need not be "sent away" or "batched" to outside laboratories; instead, sequencing and analysis 
Table 1: Clinical presentation of newborn patients

\begin{tabular}{|c|c|c|c|c|c|c|}
\hline Trio* & Enrolment & Clinical description & Family history & $\begin{array}{l}\text { Gestional age at } \\
\text { birth, } \mathrm{wk}^{+d}\end{array}$ & $\begin{array}{l}\text { Time in } \\
\text { hospital, } d\end{array}$ & $\begin{array}{l}\text { Turnaround } \\
\text { time, }+ \text { wk }\end{array}$ \\
\hline 1 & Prospective & Hydrops, bilateral pleural effusion & - & 35 & 99 & 20 \\
\hline 2 & Prospective & $\begin{array}{l}\text { Oligohydramnios, vasopressin-dependent hypotension, } \\
\text { anuric acute renal failure; at discharge, mild chronic } \\
\text { kidney disease }\end{array}$ & - & $27^{+4}$ & 119 & 58 \\
\hline 3 & Prospective & Transient neonatal hyperlactatemia & Father affected & $40^{+3}$ & 7 & 3 \\
\hline 4 & Prospective & $\begin{array}{l}\text { Epileptic encephalopathy (Ohtahara syndrome), renal } \\
\text { failure, anemia; died at } 59 \text { days of life }\end{array}$ & - & $37^{+2}$ & 59 & 2 \\
\hline 5 & Prospective & $\begin{array}{l}\text { Generalized hypotonia, horseshoe kidney, recurrent } \\
\text { apnea, nystagmus, seizures; later assessment: } \\
\text { developmental delay }\end{array}$ & - & $34^{+1}$ & 113 & 32 \\
\hline 6 & Prospective & $\begin{array}{l}\text { Bilateral inguinal hernias, flexion contractures of limbs, } \\
\text { bilateral hip dysplasia, bilateral foot clubbing; } \\
\text { early-onset multifocal seizures }\end{array}$ & - & $40^{+5}$ & 6 & 20 \\
\hline 7 & Retrospective & $\begin{array}{l}\text { Congenital trismus, feeding difficulties (gastrostomy } \\
\text { tube feeding required), limited facial expression, } \\
\text { reduced rate of blinking, limited eye movements }\end{array}$ & - & 39 & 78 & 26 \\
\hline 8 & Prospective & $\begin{array}{l}\text { Hypotonia with respiratory distress requiring } \\
\text { intubation; died at } 33 \text { days of life }\end{array}$ & $\begin{array}{l}\text { Maternal uncle } \\
\text { affected }\end{array}$ & $33^{+2}$ & 33 & 2 \\
\hline 9 & Retrospective & $\begin{array}{l}\text { Feeding difficulties and severe influx (gastrostomy tube } \\
\text { feeding required), vision impairment, left ventricular } \\
\text { cardiomyopathy; distinctive facial features with } \\
\text { synophrys; later assessment: global developmental } \\
\text { delay }\end{array}$ & $\begin{array}{l}\text { Consanguineous } \\
\text { parents }\end{array}$ & $38^{+3}$ & 34 & 18 \\
\hline 10 & Retrospective & $\begin{array}{l}\text { Cleft palate, VSD, laryngomalacia, ptosis, conductive } \\
\text { hearing loss, hypotonia, joint hypermobility, bilateral } \\
\text { hip dysplasia, pancreatic cysts, hypoplastic corpus } \\
\text { callosum; later assessment: global developmental delay, } \\
\text { short stature, scoliosis }\end{array}$ & - & $37^{+4}$ & 26 & 8 \\
\hline 11 & Retrospective & $\begin{array}{l}\text { Hydrops, bilateral hernias, bilateral hip dysplasia, short } \\
\text { limbs, brachydactyly, renal cysts, stenosis of foramen } \\
\text { magnum, horseshoe kidney }\end{array}$ & - & 28 & 32 & 6 \\
\hline 12 & Retrospective & $\begin{array}{l}\text { Choanal atresia, bilateral preaxial polydactyly, } \\
\text { multicystic kidneys, duplex left renal collecting system, } \\
\text { bicuspid aortic valve, anemia, tracheomalacia, } \\
\text { profound sensorineural hearing loss (cochlear implants } \\
\text { required), axial hypotonia; later assessment: } \\
\text { developmental delay and short stature }\end{array}$ & - & $37^{+4}$ & 22 & 7 \\
\hline 13 & Retrospective & $\begin{array}{l}\text { Macrosomia (head circumference }+4 \text { SD at birth, }+6 \text { to } \\
+7 \text { SD at } 18 \text { mo), hydrocephalus requiring shunting, } \\
\text { Chiari I malformation, hypoglycemia (transient), } \\
\text { bicuspid aortic valve }\end{array}$ & - & 31 & 4 & 24 \\
\hline 14 & Retrospective & $\begin{array}{l}\text { Cleft lip and palate, DORV with severe subpulmonary } \\
\text { stenosis and hypoplastic pulmonary valve, right renal } \\
\text { agenesis }\end{array}$ & - & $39+2$ & 41 & 22 \\
\hline 15 & Retrospective & $\begin{array}{l}\text { Ptosis, external ophthalmoplegia with right-sided } \\
\text { amblyopia and strabismus, feeding difficulties, distal } \\
\text { contractures, hypotonia, mild scoliosis, bilateral } \\
\text { cryptorchidism, hyporeflexia }\end{array}$ & $\begin{array}{l}\text { Consanguineous } \\
\text { parents }\end{array}$ & $37^{+5}$ & 53 & 5 \\
\hline 16 & Retrospective & $\begin{array}{l}\text { Hypotonia; later assessment: global developmental } \\
\text { delay, averbal, short stature, seizures }\end{array}$ & - & $37^{+2}$ & 12 & 9 \\
\hline 17 & Retrospective & $\begin{array}{l}\text { Hypotonia, congenital diaphragmatic hernia, feeding } \\
\text { issues, flexion contracture of right third to fifth digits, } \\
\text { torticollis; later assessment: developmental delay }\end{array}$ & - & $38^{+1}$ & 75 & 15 \\
\hline 18 & Retrospective & $\begin{array}{l}\text { IUGR, microcephaly, bilateral flexion contractures of PIP } \\
\text { and DIP of third fingers, bilateral ankle contractures, } \\
\text { hypertonicity, enlarged cisterna magna, dysmorphic } \\
\text { facies; later assessment: global developmental delay }\end{array}$ & $\begin{array}{l}\text { Consanguineous } \\
\text { parents }\end{array}$ & $36^{+3}$ & 23 & 3 \\
\hline 19 & Prospective & $\begin{array}{l}\text { Congenital diaphragmatic hernia, nephrotic syndrome, } \\
\text { nondysmorphic }\end{array}$ & - & $38^{+2}$ & $\begin{array}{l}\text { Still in } \\
\text { hospital }\end{array}$ & 17 \\
\hline 20 & Retrospective & $\begin{array}{l}\text { Tetralogy of Fallot, hypotonia; later assessment: global } \\
\text { developmental delay, pica }\end{array}$ & - & $40^{+1}$ & 6 & 8 \\
\hline \multicolumn{7}{|c|}{$\begin{array}{l}\text { Note: } \mathrm{DIP}=\text { distal interphalangeal joint, } \mathrm{DORV}=\text { double outlet right ventricle, IUGR }=\text { intrauterine growth retardation, } \mathrm{PIP}=\text { proximal interphalangeal joint, } \\
\mathrm{SD}=\text { standard deviation, } \mathrm{VSD}=\text { ventricular septal defect. } \\
{ }^{*} \text { Trio }=\text { newborn }+ \text { parents. } \\
\text { †Time to return of test results. }\end{array}$} \\
\hline
\end{tabular}


can be performed locally, in a potentially shorter time frame, which is of particular importance for the care of critically ill neonates without a diagnosis. This approach also facilitates input and collaboration from the most-responsible bedside physician, to enable efficient genotypephenotype correlation.

The focused panel approach is more consistent with the local use of microarrays, a test that is often available in tertiary care centres and can be performed with a return of results within days to weeks after blood sampling. Quantitative fluorescence polymerase chain reaction techniques can also be performed with a rapid return of results when there is suspicion of aneuploidy, such as trisomy 21,18 or 13 .
The Canadian College of Medical Geneticists published a position statement on the clinical application of genome-wide sequencing approaches for the clinical care of patients in whom rare diseases are suspected. ${ }^{14}$ This statement recommended that genome-wide data be further refined by computer-based filtering to include only those genes relevant to the particular clinical presentation, to minimize the risk of identifying an incidental finding (a genetic variant unrelated to the primary indication for testing). In addition, the focused interrogation of selected genes can dramatically reduce the number of variants requiring interpretation in the clinical setting. Our disease-focused next-generation sequencing approach, which had 4813 genes, can thus be

Table 2: Clinical investigations performed for each study participant

\begin{tabular}{|c|c|}
\hline Trio* & Diagnostic work-up \\
\hline 1 & $\begin{array}{l}\text { Karyotype, rapid aneuploidy detection, chromosomal microarray, pAA, uOA, lysosomal enzyme work-up, MPS testing, } \\
\text { Noonan panel (13 genes), thrombophilia workup }\end{array}$ \\
\hline 2 & Karyotype, chromosomal microarray, uAA \\
\hline 3 & $\begin{array}{l}\text { Acylcarnitine profile, pAA, uOA, pyruvate dehydrogenase and pyruvate carboxylase levels, respiratory chain enzymology } \\
\text { (reduced activity of complex I and IV), lactate }(19.8 \mathrm{mmol})\end{array}$ \\
\hline 4 & $\begin{array}{l}\text { Sequencing of nuclear encoded mitochondrial gene panel, mitochondrial point mutation analysis, lactate carnitine, } \\
\text { acylcarnitine, VLCFA, TIF, pAA, uOA, biotinidase, pyruvate dehydrogenase, pyruvate carboxylase, alpha amino adipic } \\
\text { semialdehyde, MRI and metabolic workup suggestive of a mitochondrial disease }\end{array}$ \\
\hline 5 & $\begin{array}{l}\text { Chromosomal microarray, SLC2A1 sequencing, pAA, uOA, carnitine, acylcarnitine profile, VLCFA, MPS, TIF, neurotransmitter } \\
\text { metabolites, MECP2 testing, cerebrospinal fluid (pyruvate, lactate, total protein, glucose, organic and amino acids) }\end{array}$ \\
\hline 6 & Chromosomal microarray, cutis laxa autosomal recessive panel (6 genes), uOA, pAA, MPS and oligosaccharide screening \\
\hline 7 & Chromosomal microarray, muscle biopsy, MRI, MYH8 testing \\
\hline 8 & MTM1 sequencing, uOA, pAA \\
\hline 9 & Karyotype, chromosomal microarray, Prader-Willi testing, MPS and oligosaccharide screening, TIF, serum B-hexosaminidase \\
\hline 10 & Chromosomal microarray, Costello syndrome testing (HRAS), acylcarnitine profile, Noonan panel (13 genes) \\
\hline 11 & $\begin{array}{l}\text { Rapid aneuploidy detection, chromosomal microarray, uOA, acylcarnitine profile, MPS and oligosaccharidosis screening, } \\
\text { VLCFA, TIF, 7DHC, galactosemia, sequencing and deletion/duplication analysis for IFT180 and DYNC2H1 }\end{array}$ \\
\hline 12 & $\begin{array}{l}\text { Karyotype, chromosomal microarray, 7DHC, CHD7 and FANCA squencing, Diamond Blackfan anemia panel, FISH for } 22 q 11 \\
\text { deletion }\end{array}$ \\
\hline 13 & Karyotype; chromosomal microarray; Noonan panel (13 genes); PTEN, PIK3CA and AKT1 testing \\
\hline 14 & Chromosomal microarray, CHD7 testing \\
\hline 15 & $\begin{array}{l}\text { Karyotype, FISH for chromosome } 18, \mathrm{X} \text { and } \mathrm{Y} \text {, chromosomal microarray, DMPK expansion detection, uOA, CK, lactate, SMN1 } \\
\text { and SMN2 deletion testing, MTM1 sequencing, EMG, NCS, muscle biopsy, oxidative phosphorylation testing, mitochondrial } \\
\text { DNA testing, congenital myasthenic syndrome panel }\end{array}$ \\
\hline 16 & $\begin{array}{l}\text { Karyotype, chromosomal microarray, TIF, pAA, uOA, 7DHC, KMT2D testing, Angelman syndrome testing, TCF4 testing, } \\
\text { EHMT1 testing }\end{array}$ \\
\hline 17 & $\begin{array}{l}\text { Chromosomal microarray, DMPK expansion testing, Prader-Willi testing, pAA, uOA, carnitine, acylcarnitine profile, VLCFA, } \\
\text { muscle biopsy }\end{array}$ \\
\hline 18 & Karyotype, chromosomal microarray \\
\hline 19 & Karyotype, chromosomal microarray \\
\hline 20 & Karyotype, chromosomal microarray, FISH for 22q11 deletion \\
\hline \multicolumn{2}{|r|}{$\begin{array}{l}\text { Note: } \mathrm{CK}=\text { creatine kinase, EMG = electromyography, FISH = fluorescence in situ hybridization, MPS = mucopolysaccharide, MRI = magnetic resonance imaging, } \\
\text { NCS }=\text { nerve conduction studies, PAA = plasma amino acids, TIF = transferrin isoelectric focusing, UAA = urinary amino acid, uOA = urinary organic acid, VLCFA = } \\
\text { very long chain fatty acids, 7DHC = 7-dehydrocholesterol. } \\
\text { *Trio = newborn + parents. }\end{array}$} \\
\hline
\end{tabular}


further refined to focus only on genes that would be responsible for disease in a neonate. We visually inspected another focused, commercially available panel of 2742 genes (SureSelect Inherited Disease panel, Agilent Technologies), and found all 8 of the genes identified in our patients. If we assume that coverage is the same (if not better) with the commercially available panel, a similar diagnostic rate can be expected, despite the exclusion of more than 2000 genes. In our study, we did not identify any incidental findings, but the risk of doing so would be minimized by using a refined, panel-based strategy that is tailored specifically for the NICU.

The feasibility of next-generation sequencing in the NICU and its diagnostic success rate have yet to be extensively studied in a prospective manner, and there are multiple approaches that could be used for such future studies. If suitable resources are available, whole-genome sequencing can provide a comprehensive test and rapid generation of data. This approach was studied in another NICU setting, with confirmation of diagnosis in 2 days in a retrospective sample of 2 children with a known genetic disease. ${ }^{15}$ Additional diagnoses were possible in NICU inpatients when parents were included in the testing. ${ }^{15}$ In a study of whole-genome sequencing in children retrospectively identified after an inpatient stay in either the neonatal or pediatric intensive care unit, a diagnosis was achieved in $57 \%$ (20/35) of cases. ${ }^{11}$ These whole-genome sequencing studies required high-throughput sequencers, bioinformatics support, automation and experts in the field of translational genomics, resources that are not readily available to most diagnostic laboratories at this time. Another option, whole-exome sequencing, focuses on the protein coding regions of the approximately 22000 human genes.

However, interpretation of variants identified by whole-exome and whole-genome sequencing can be a challenge in a clinical setting, because three-quarters of the known genes assessed are not associated with human disease. There is less uniform coverage in whole-exome sequencing, and up to $10 \%$ of the region of interest may not be adequately covered. ${ }^{16}$ Thus, although wholeexome and whole-genome sequencing are amenable to novel gene discovery, the time frame required for characterization and validation of a novel gene is often too long to be of practical help for sick neonates.

\section{Limitations}

This pilot project involved a small sample of 20 patients who were highly selected for admission to the NICU for genetic causes. Further study will include testing in expanded cohorts to evaluate diagnostic rates for the varied clinical presentations seen in the NICU. Determination of the clinical presentations best served by nextgeneration sequencing in the NICU will be helpful for future testing.

Table 3: Details of mutations identified in patients with a positive molecular diagnosis

\begin{tabular}{|c|c|c|c|c|c|c|c|}
\hline Trio* & Sex & $\begin{array}{l}\text { Affected } \\
\text { gene }\end{array}$ & Inheritance & $\begin{array}{l}\text { Mutation } \\
\text { type }\end{array}$ & NCBI RefSeq & CDNA and protein changes identified & $\begin{array}{l}\text { Molecular diagnosis } \\
\text { (OMIM no.) }\end{array}$ \\
\hline \multirow[t]{2}{*}{2} & \multirow[t]{2}{*}{ M } & \multirow[t]{2}{*}{$A C E$} & \multirow[t]{2}{*}{$\begin{array}{l}\text { Compound } \\
\text { heterozygous }\end{array}$} & $\begin{array}{l}\text { Frameshift } \\
\text { deletion }\end{array}$ & NM_000789.3 & c.819_820delAG; p.(Arg274Glyfs*117) & \multirow[t]{2}{*}{$\begin{array}{l}\text { Renal tubular dysgenesis } \\
(106180)\end{array}$} \\
\hline & & & & $\begin{array}{l}\text { Frameshift } \\
\text { deletion }\end{array}$ & NM_000789.3 & c.3521delG; p.(Gly1174Alafs*12) & \\
\hline 6 & $\mathrm{M}$ & SCN1A & De novo & Missense & NM_001202435.1 & c.620T>G; p.(Val207Gly) & $\begin{array}{l}\text { SCN1A-related } \\
\text { encephalopathy syndrome } \\
(607208)\end{array}$ \\
\hline 8 & $\mathrm{M}$ & MTM1 & X-linked & Nonsense & NM_000252.2 & c.584C>A; p. $($ Tyr 198*) & $\begin{array}{l}\text { Myotubular myopathy, } \\
\text { X-linked (310400) }\end{array}$ \\
\hline 9 & $\mathrm{~F}$ & FTO & $\begin{array}{l}\text { Autosomal } \\
\text { recessive }\end{array}$ & Missense & NM_001080432.2 & c.956C>T; p.(Ser319Phe) & $\begin{array}{l}\text { FTO deficiency syndrome } \\
(612938)\end{array}$ \\
\hline \multirow[t]{2}{*}{11} & \multirow[t]{2}{*}{ M } & \multirow[t]{2}{*}{ WDR19 } & \multirow{2}{*}{$\begin{array}{l}\text { Compound } \\
\text { heterozygous }\end{array}$} & Nonsense & NM_025132.3 & c.1600G>T; p.(Glu534*) & \multirow{2}{*}{$\begin{array}{l}\text { Cranioectodermal dysplasia } \\
(614376)\end{array}$} \\
\hline & & & & Missense & NM_025132.3 & c.2129T>C; p.(Leu710Ser) & \\
\hline 15 & $\mathrm{M}$ & CHRND & $\begin{array}{l}\text { Autosomal } \\
\text { recessive }\end{array}$ & Splice site & NM_000751.2 & c. $932+5 G>A ; p . ?$ & $\begin{array}{l}\text { Congenital myasthenic } \\
\text { syndrome (601462) }\end{array}$ \\
\hline 18 & M & DYRK1A & De novo & Splice site & NM_001396.3 & c.951+4_951+7delAGTA; p.? & $\begin{array}{l}\text { Autosomal dominant } \\
\text { intellectual disability } \\
\text { syndrome type } 7 \text { (614104) }\end{array}$ \\
\hline 19 & $\mathrm{~F}$ & WT1 & De novo & Missense & NM_024426.4 & c.1460A>C; p.(His469Pro) & $\begin{array}{l}\text { Denys-Drash syndrome } \\
(194080)\end{array}$ \\
\hline
\end{tabular}


An assessment of the timing of return of results as a primary outcome measure was not part of the current study but would also be beneficial, as this factor may substantially affect patient care. Similarly, an evaluation of the "best time" to pursue next-generation sequencing is needed, to decide whether this method should be used as a first-tier test in the NICU or as a final investigation in an outpatient clinic. An expanded sample of patients, identified consecutively, prospectively and with appropriate controls, will help to answer the questions of who should be offered next-generation sequencing, and when.

\section{Conclusion}

The results of this study highlight the potential impact of next-generation sequencing on both patient care and health care systems. Insurers are faced with increasing costs of genetic testing because of rapidly expanding knowledge about the genetic causes of rare diseases. A single, targeted, disease-relevant panel, such as the one used here, could potentially address the testing needs for a sick child at a fraction of the current cost. The availability and accessibility of approaches similar to the one reported here could also strongly affect the timing of health care delivery. Improving the time to diagnosis could substantially alter the role of medical genetics in acute management. ${ }^{11}$ Integration of next-generation sequencing will enable molecular diagnosis during the hospital stay soon after birth, instead of families having to wait months to years for a diagnosis, which is the current norm.

\section{References}

1. Kole A, Faurisson F. Rare diseases social epidemiology: analysis of inequalities. Adv Exp Med Biol 2010;686:223-50.

2. Innes AM, Boycott KM. Next generation diagnostics for rare neurological diseases: the future is here. Can J Neurol Sci 2014;41:299-300.

3. Scriver CR, Neal JL, Saginur R, et al. The frequency of genetic disease and congenital malformation among patients in a pediatric hospital. CMAJ 1973;108:1111-5.

4. Synnes AR, Berry M, Jones H, et al. Infants with congenital anomalies admitted to neonatal intensive care units. Am J Perinatol 2004;21:199-207.

5. Stewart DL, Hersh JH. The impact of major congenital malformations on mortality in a neonatal intensive care unit. $J K y$ Med Assoc 1995;93:329-32.

6. Shashi V, McConkie-Rosell A, Rosell B, et al. The utility of the traditional medical genetics diagnostic evaluation in the context of next-generation sequencing for undiagnosed genetic disorders. Genet Med 2014;16:176-82.
7. Graungaard AH, Skov L. Why do we need a diagnosis? A qualitative study of parents' experiences, coping and needs, when the newborn child is severely disabled. Child Care Health Dev 2007;33:296-307.

8. Boycott KM, Vanstone MR, Bulman DE, et al. Rare-disease genetics in the era of next-generation sequencing: discovery to translation. Nat Rev Genet 2013;14:681-91.

9. Lee H, Deignan JL, Dorrani N, et al. Clinical exome sequencing for genetic identification of rare Mendelian disorders. JAMA 2014;312:1880-7.

10. Yang Y, Muzny DM, Xia F, et al. Molecular findings among patients referred for clinical whole-exome sequencing. JAMA 2014;312:1870-9.

11. Willig LK, Petrikin JE, Smith LD, et al. Whole-genome sequencing for identification of Mendelian disorders in critically ill infants: a retrospective analysis of diagnostic and clinical findings. Lancet Respir Med 2015;3:377-87.

12. Saudi Mendeliome Group. Comprehensive gene panels provide advantages over clinical exome sequencing for Mendelian diseases. Genome Biol 2015;16:134.

13. Richer J, Daoud H, Geier P, et al. Resolution of refractory hypotension and anuria in a premature newborn with loss-offunction of ACE. Am J Med Genet A 2015;167A:2867.

14. Boycott K, Hartley T, Adam S, et al.; Canadian College of Medical Geneticists. The clinical application of genome-wide sequencing for monogenic diseases in Canada: position statement of the Canadian College of Medical Geneticists. J Med Genet 2015;52:431-7.

15. Kingsmore SF, Saunders CJ. Deep sequencing of patient genomes for disease diagnosis: When will it become routine? Sci Transl Med 2011;3:87ps23.

16. Ankala A, da Silva C, Gualandi F, et al. A comprehensive genomic approach for neuromuscular diseases gives a high diagnostic yield. Ann Neurol 2015;77:206-14.

Affiliations: Department of Genetics (Daoud, Luco, Beaulieu, Jarinova, Carson, Nikkel, Graham, Richer, Armour, Boycott, Dyment) and Department of Pediatrics (Bulman, Chakraborty, Geraghty, Lines, Lacaze-Masmonteil), Children's Hospital of Eastern Ontario, Ottawa, Ont.; McGill University (Li, Bareke, Majewski) and Genome Quebec Innovation Centre (Li, Bareke, Majewski), Montréal, Que.

Contributors: Hussein Daoud, Stephanie Luco, Jacek Majewski, Kym Boycott and David Dyment conceived the study design. All of the authors contributed to the analysis and interpretation of the data, with Hussein Daoud, Stephanie Luco, Rui Li, Eric Bareke, Jacek Majewski and David Dyment interpreting the sequence data. Hussein Daoud, Kym Boycott and David Dyment drafted the manuscript. All of the authors provided critical review of the manuscript, approved the final version for publication and agreed to act as guarantors of the work.

Funding: This work was performed under a grant from the Children's Hospital of Eastern Ontario Academic Health Science Centres AFP Innovation Fund and was supported in part by the Care4Rare Canada Consortium, which is funded by Genome Canada, the Canadian Institutes of Health Research (CIHR), the Ontario Genomics Institute, Ontario Research Fund, Genome Quebec and the Children's Hospital of Eastern Ontario Foundation. Kym Boycott and David Dyment are supported by CIHR Institute of Genetics Clinical Investigatorship Awards.

Acknowledgements: The authors thank the patients and families, without whom this work would not have been possible. They also acknowledge Wen Qin and Wendy Mears for variant validation. 